\title{
Culture, climate change and mobility decisions in Pacific Small Island Developing States
}

\section{Robert Oakes ${ }^{1}$}

Published online: 17 May 2019

(C) Springer Nature B.V. 2019

\begin{abstract}
The Pacific Small Island Developing States are often considered on the frontline of climate change due to high levels of exposure to climate-related hazards and limited adaptive capacity to respond. In this context, Pacific Islanders may be displaced, or choose to migrate to escape risk and find more secure livelihoods. On the other hand, Pacific political and community leaders stress that mobility can be a threat to sovereignty and culture and should only be considered as a last resort. This paper adopts a cultural ecology framing to gain a greater understanding of these contested local discourses on climate change and human mobility in Kiribati, Tuvalu and Nauru through the use of the $\mathrm{Q}$ method. The results reveal a range of shared subjective understandings of climate change and human mobility which show that reasons for, and perceived outcomes of moving are inextricably linked. These subjective understandings highlight that culture, and in particular how Islanders relate to land and religion can influence decision-making, promoting or hindering mobility. The findings therefore support the need for further engagement with communities to recognise and validate their positions on climate change and human mobility to facilitate the planning and implementation of effective policy.
\end{abstract}

Keywords Migration climate Pacific SIDS culture Q method

\section{Introduction}

For more than two decades, it has been theorised that climate change will result in increased human mobility, with millions of people moving both internally and internationally away from hazards and marginal environments to places where they can find more secure livelihoods (Myers 1993; Tacoli 2009; Rigaud et al. 2018). Such flows

Robert Oakes

oakes@ehs.unu.edu

1 United Nations University Institute for Environment and Human Security (UNU-EHS), UN

Campus, Platz der Vereinten Nationen 1, 53113 Bonn, Germany 
have implications for planning and social policy and are often framed around the issue of human or national security (Bettini 2014). This creates a strong desire both within affected states and the international community to better understand climate-related mobility (UNFCCC 2015).

The Pacific Small Island Developing States (SIDS) of Kiribati, Tuvalu and Nauru are at the forefront of climate change and human mobility (Farbotko and Lazrus 2012). Due to their location and topography, they are exposed to climate change-related hazards. As developing countries, they have comparatively low economic and technical ability to adapt and respond (IPCC 2014). The situation for Kiribati and Tuvalu is particularly acute; their low-lying land is exposed to sea level rise and they are recognised by the United Nations as least developed countries (LDCs) with limited resources (UNCTAD 2018). They also have limited opportunities to move internationally, meaning domestic flows of mobility combine with high birth rates to cause unsustainable population growth in the capitals of South Tarawa and Funafuti (Locke 2009; Ash and Campbell 2016). A ‘triple jeopardy' of climate change, economics and demography therefore suggests that Pacific SIDS are in a state of increased risk (Hugo 2011, p. 531). As a result, dominant discourses in the Global North explicitly or implicitly suggest Pacific SIDS governments and their residents are inherently lacking the agency to help themselves and are dependent on aid to adapt to climate change or move (Barnett and Campbell 2010; Hirsch 2015).

In contrast, representatives of these nations are increasingly unwilling to represent themselves as helpless victims (Weber 2015). The Pacific SIDS community has sought to move the discourse from that of "environmental refugees" and narratives of extinction (Farbotko and Lazrus 2012) and even Nations ex situ (Burkett 2011), to more agential understandings of mobility. Indeed, the Government of Kiribati has refused to support its citizens, the I-Kiribati, in legal claims for climate refugee status, instead of promoting more positive outlooks such as dignified forms of migration (Voigt-Graf and Kagan 2017).

However, it would be wrong to suggest that dignified migration is the end goal for Pacific SIDS. Islanders have a strong desire to stay on their islands and in their countries. This point of view was recently expressed by the Prime Minister of Tuvalu:

'While we talk of migration, we should not give the impression that people want to leave their homelands. Maintaining sovereignty, self-determination, cultural identity and territorial rights are of primary concern to Pacific Islanders'.

(Sopoanga 2016)

Views about climate-related mobility in Pacific SIDS are therefore multifaceted and can be contradictory. They are characterised by climate risk, vulnerability and adaptation, but also less tangible and more personal concepts such as home, place and sovereignty. The present article attempts to reveal the manifold ways in which Pacific Islanders understand these issues, responding to the lack of studies into subjective understandings of climate-related decision-making (Adger et al. 2013). In this study, subjective understandings are defined as the very personal interpretations of information as it interacts with, and is conditioned by, environmental, social, psychological and especially cultural elements. A cultural ecological framing (Steward 1972) is used to explore this process and respond to the deficit of research 'foregrounding islander perspectives' (Farbotko and Lazrus 2012, p. 388).

As a result, the core research question which guides this study can be stated as follows: 
What are Pacific SIDS residents' subjective understandings of climate change and mobility?

To address this question, the research team conducted interviews with a range of household heads in Kiribati, Tuvalu and Nauru. The team used Q method, a research tool designed to understand subjectivity (Brown 1980) and found that there are a range of cultural factors which influence the way in which Pacific Islanders understand climate change and mobility. Specifically, religion and the way people relate to island culture and land have an influence on subjective understandings and so the desirability and likelihood of moving. The paper concludes that a deeper knowledge of Pacific SIDS residents' subjective understandings of climate change and mobility will allow policy makers to be more responsive to residents' desires and interests.

The paper continues with "Literature review", a discussion of the existing literature on mobility and climate change and cultural ecology is introduced as the theoretical framing for examining the relationships between the environment, mobility and culture. "Study areas" discusses the case study areas of Kiribati, Tuvalu and Nauru and "Method and data" introduces Q method and describes its use in the study. "Results" presents the results by country and "Discussion" explores the role of culture on subjective understandings of climate change and mobility. Finally "Conclusion and policy implications" summarises the contribution of the paper and implications for policy.

\section{Literature review}

Climate-related mobility decisions are increasingly understood as taken in a dynamic economic, political, social and cultural context which interacts with environmental intensifiers or immediate triggers (Foresight 2011). The United Nations Framework Convention on Climate Change categorises climate-related mobility according to the level of the agency involved in the decision to move (UNFCCC 2017). Displacement occurs when there is little option but to move (IDMC 2017) and voluntary migration occurs when the decision to move is linked to deteriorating environmental conditions (Warner and Afifi 2014). In this paper, 'mobility' is used as a general term for movement whilst 'migration' is used to convey more agential movements in line with the UNFCCC (2017), with the caveat that the voluntariness of any environment-related mobility is questionable (Hugo 2011). Planned relocation or resettlement refers to community level movements planned and carried out by administrative authorities to reduce climate exposure (Brookings and UNHCR 2015). Climate change might also restrict mobility as those dependent on the environment could experience an erosion of capital necessary for moving (Foresight 2011). Therefore, some people may find themselves in a doublebind; those with the greatest need to move are also the least able to and have been termed 'trapped' (Warner and Laczko 2008; Black and Collyer 2014).

Migration researchers have investigated the consequences of climate change-related movements for migrants, households and sending and receiving communities (Gemenne and Blocher 2017). Research finding that voluntary migration brings benefits broadly supports framing of migration as a form of adaptation (IOM 2017). Recent research in Pacific SIDS has supported this position with evidence of migration 
providing remittances (Shen and Gemenne 2011), education and employment opportunities for young people (Goldsmith 2015) and being complementary to other adaptive measures (Ash and Campbell 2016). An alternative view is that such movements are not attempts at adaptation, so much as acts of survival whereby people are compelled to leave homes and families with implications for rights, livelihoods and physical, emotional and psychological health (Bettini 2014; Kelman et al. 2015; Unicef 2017). For example, in Pacific SIDS, internal migration often involves moving to capital islands which can intensify existing issues concerning water and sanitation (Storey and Hunter 2010; Connell 2011; Ash and Campbell 2016). In summary, impacts for migrants, households and sending and receiving communities are context specific and can be positive, negative or even both (Gemenne and Blocher 2017).

Migration with dignity is an emerging concept (McNamara 2015) which may provide a key to understanding and framing mobility without terming the movement adaptive or otherwise. Migration with dignity originated with the Government of Kiribati and centres on proactive migration instead of displacement, with upskilled migrants being active, productive participants in the global economy (Voigt-Graf and Kagan 2017). In this way, it might be possible to maximise benefits of migration, minimise loss and damage that movements can entail and circumvent the impacts of victimisation framings on efforts to mitigate and adapt to climate change (Ransan-Cooper et al. 2015). When considering migration with dignity, it is useful to recognise that whether a person possesses dignity depends on personal values, beliefs and opinions. This belies the importance of considering subjectivity in understanding mobility.

The field of environmental mobility was originally informed from the broader migration literature which often failed to recognise subjectivity. Instead, migration was assumed to be a broadly rational response to push and pull factors (Piore 1979; Stark and Bloom 1985; Borjas 1989; Massey et al. 1993). However, it has also been argued for decades that migration is culturally produced and expressed (Fielding 1992) and recently less economically rational behaviour has become more prominent in research (Scott 2006; Verwiebe 2014) with emotions explored as a driver of mobility (Svašek 2010). Despite these advances and the nuances of the Foresight Model (2011), in policy and academia alike, environment-related mobility is often represented as determined by the environment and conditioned by the economy. The prevalence of terms such as adaptive capacity and resilience as enablers of mobility and vulnerability as a constraint on adaptation (Oliver-Smith 2016) is indicative of the dominance of the measurable over the abstract, as limitations are often understood as structural and not agential (Adger et al. 2009).

In the broader fields of environmental risk and hazards, it has long been argued that risk and responses are defined and shaped by processes of cognition (Slovic 2000; Kahneman 2012), culture (Douglas 1992) and the combination of the two (Kahan et al., 2007). People are not automatons or economically rational, rather responses are influenced by worldviews (Oliver-Smith 1996; McIvor and Paton 2007), trust in the messenger (Drabek 1986; Kasperson et al. 1988) in addition to ethnicity, income and other socio-economic indicators (Peacock et al. 1997; Lindell et al. 2005). Similarly, whether and how people, households and communities adapt to climate risk can be related to their cognitive processes and attitudes (Grothmann and Patt 2005) and therefore barriers to adaptation can be endogenous, that is existing within people and society as opposed to merely exogenous, or structural (Adger et al. 2009). 
The last decade has seen the genesis of research into subjective understandings of climate and mobility in Pacific SIDS. These studies have highlighted the importance of culture, specifically how people relate to religion and land (Farbotko 2005; Connell 2013; Smith 2013; McCubbin et al. 2015; Nunn et al. 2016). One way to understand this process is through the material approach of cultural ecology, in which cultures are 'systems (of socially transmitted behavior patterns) that serve to relate human communities to their ecological settings' (Keesing 1974, p. 75). According to Steward (1972), the environment influences technologies and demography and this infrastructure leads to the development of economic and political structures, which in turn shape the development of superstructural worldviews and ideologies including religions. The model also has a role for the agency; through the cognised environment, people perceive the environment in such a way as to adapt to its challenges (Steward 1972). Cultural ecology can therefore link to ideational models which consider culture as a cognitive system (Berry 2018), with a culture defined as 'the form of things that people have in mind, their models for perceiving, relating, and otherwise interpreting them' (Goodenough 1957, p. 167).

Religion is an example of how a cognitive system or superstructure can pose a barrier to adaptation and mobility. When I-Kiribati make significant financial contributions to religious institutions they have less money for other expenses (Kuruppu 2009). Religion is also a major cultural force in Tuvalu, with $93 \%$ of the population affiliated to the main Christian denomination, Ekalesia Kelisiano Tuvalu (McCubbin et al. 2015). Farbotko (2005) found that some Tuvaluans believe God will protect them from flooding due to the covenant with Noah, a worldview which may prevent the acceptance of sea level rise (Kelman et al. 2015). The Church has been working to characterise the flood and covenant with Moses as allegorical, as opposed to literal (Shen and Gemenne 2011) with mixed results (Mortreux and Barnett 2009).

The relevance of cultural ecology for this study is further supported by findings that relationships people have with land influence whether, and how they respond to environmental risks (Adger et al. 2011). In the Pacific, the way Islanders relate to land is central to culture (McCubbin et al. 2015; Farbotko et al. 2015), with land valued above and beyond the livelihoods which the land bestows (Adams 2016). This is most clearly shown by the Tuvaluan concept of fenua, defined as 'a set of customary practices and territorial markers...the biogeographical location of identity in place' (Stratford et al. 2013, p. 69). Fenua may explain why some Tuvaluans are unwilling to consider migration, let alone relocation due to strong place attachment and perceived risks to sovereignty and cultural identity (Mortreux and Barnett 2009). Such findings could explain why a range of adaptation measures are being pursued in Kiribati aside from migration (Allgood and McNamara 2017) and why people in Tuvalu may stay and "voice" their concerns about climate change, as opposed to 'exit' (Noy 2017).

Fenua or place attachment more generally is a sentiment that does not necessarily prevent mobility away from a place. People may become inclined to move when their perception of place utility in destination areas outweighs the anchoring force of home (Adams 2016). People may also attempt to disentangle themselves emotionally from a place if they perceive risk, and in turn try to form new attachments in destination areas before moving to ease transitions (Agyeman et al., 2009). However, if a person perceives a place as other, then they will associate it as more risky than familiar regions, even if the level of objective risk is the same (Nunn et al. 2016). This suggests that staying can be an agential (if not economically 
rational) decision, which should not be conflated with the idea of being trapped by socioeconomic status (Oakes 2014; Adams 2016). Therefore, a more inclusive term for those not moving under environmental risk is 'immobile' (Zickgraf 2018), as it can encompass the constraints of those unable to move but also the strength of place attachment or related concepts such as fenua.

The centrality of land and thus the importance of fenua for Pacific SIDS is also evident in the history of relocations in the region. As Connell (2012: p. 138) puts it 'wherever resettlement has occurred, social tensions have followed... [and] have been greatest where migration has crossed cultural boundaries'. There has been friction since 2000 I-Kiribati were relocated to the Solomon Islands in the mid-twentieth century (Donner 2015), whilst Nauruans rejected resettlement to an island off the coast of Queensland due to the potential loss of national identity (Tabucanon and Opeskin 2011). On the other hand, resettlement of Tuvaluans from Vaitupu to Fiji has been viewed as successful due to the fertile land provided and the importation of culture and community leadership (Tabucanon 2012), indicating how fenua may facilitate mobility (Stratford et al. 2013).

Whilst the pull of the land is powerful, mobility has been of vital significance to the economies, societies and cultures of Pacific SIDS for thousands of years (Kirch 2017). In more recent times, due to their remoteness and lack of economic opportunities, the three countries have been termed MIRAB (MIgration, Remittances and Bureaucracy) economies (Bertram 1999) as they are heavily dependent on income from migrants and the state. Mobility is therefore a common livelihood strategy, even without considering the impact of climate change (Voigt-Graf and Kagan 2017). Such movements have fostered networks and outward-looking stances which could make climate-related mobility more palatable for potential migrants.

The combination of climate risk and mobility therefore produces deep and rich discourses in Pacific SIDS. Climate-related mobility occurs along a continuum of agency and can have a range of impacts. The ways people perceive climate change and mobility, and so make decisions are conditioned by the environment and social structures but are also differentiated, subjective and relate to culture. The following section provides more contexts for these processes by introducing the study areas of Kiribati, Tuvalu and Nauru.

\section{Study areas}

The research behind this paper was carried out as part of the EU-funded Pacific Climate Change and Migration (PCCM) project. Kiribati, Tuvalu and Nauru were selected as target countries as they are recognised as particularly at risk from climate change, whilst migration has been promoted as a form of adaptation by the states (McNamara 2015) and international organisations (UNESCAP 2014). As such there was a desire for new data to inform policy.

Kiribati, Tuvalu and Nauru are positioned close to the equator in the Pacific Ocean (Fig. 1). The Republic of Kiribati had a population of 110,136 in 2015, up from 103,058 in 2010 (Republic of Kiribati 2016). The country is spread over an area of 3.5 million $\mathrm{km}^{2}$ of the ocean in Micronesia. It is made up of islands in the Gilbert, Phoenix and Line groups, with a land area of $811 \mathrm{~km}^{2}$. Banaba Island is the only raised 


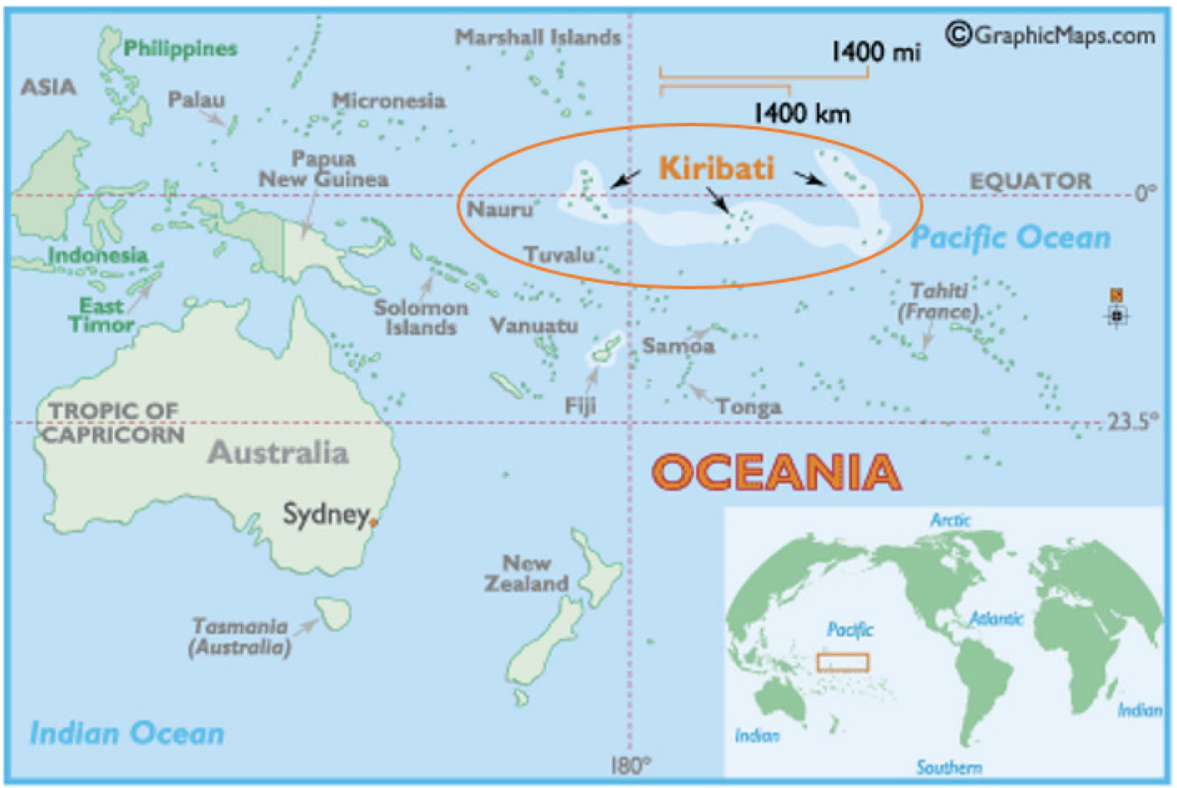

Fig. 1 Location of Kiribati, Tuvalu and Nauru in the Pacific Ocean. World Atlas (nd)

coral island, with an elevation of $81 \mathrm{~m}$; the other 32 islands are low-lying atolls. Tuvalu is in Polynesia and had a population of 10,837 in 2012, having increased from 9561 in 2002 in (Government of Tuvalu 2015). It is one of the world's smallest and most isolated island nations and comprises 9 inhabited atolls and reef islands. The total land area is $26 \mathrm{~km}^{2}$ with the highest elevation approximately $5 \mathrm{~m}$ above sea level. The Republic of Nauru is the world's smallest island state situated in Micronesia and is a raised coral atoll of $21 \mathrm{~km}^{2}$ with 10,084 inhabitants, the population rising from 9233 in 2006 (Republic of Nauru 2011). The highest elevation in Nauru is $61 \mathrm{~m}$. It has limited groundwater, much of which has been contaminated by wastewater and other pollutants. The interior of Nauru ( $80 \%$ of the total land) is uninhabitable due to heavy phosphate mining, thus Nauru's population lives on the coast.

Climate change is already impacting Pacific SIDS. Since 1993, most of the region has experienced an annual sea level rise of about $4 \mathrm{~mm}$ per year (CSIRO 2011). Throughout the twenty-first century, climate projections for the region forecast further sea level rise which will contribute to more extreme sea-level events as impacts of king tides and storm surges are compounded (IPCC 2014). Ocean acidification poses a threat to the region's marine environment and coral reef systems, which are already experiencing coral bleaching, impacting fishing activities (Manzello et al. 2017). It is projected that annual rainfall may increase, including more severe and more frequent days of extreme rainfall. Nonetheless, irregular rainfall and periods of drought could become more common (IPCC 2014). Both mean and extreme atmospheric temperatures are set to increase (CSIRO 2011). Tropical storms may become more intense as thermodynamic potential rises with warming oceans (CSIRO 2011).

Current mobility flows are distinct for each country and are described in detail in the PCCM Case Study Reports. In Nauru, due to the size of the country, movement is international, primarily to Fiji and Australia (Campbell et al. 2016). In Tuvalu, 
movement is overseas, primarily to Fiji and New Zealand and internal from the outer islands to Funafuti the capital (Milan et al. 2016). In Kiribati, mobility is less common than in the other two countries and tends to be domestic, with large numbers moving to the capital South Tarawa from the outer islands. International mobility, such as exists, is mainly to New Zealand and Fiji (Oakes et al. 2016). The three governments are involved in various schemes to promote labour and educational migration to Australia and New Zealand. However, they can only satisfy a fraction of the demand for migration, as quotas are in the hundreds, as opposed to the thousands.

Climatic, economic and demographic trends thus combine with political realities to suggest that growing populations in Pacific SIDS will become increasingly exposed and vulnerable to the impacts of climate change. In this context, it is imperative to highlight the subjectivity in perception and decision-making to recognise and maximise the agency of Pacific Islanders.

\section{Method and data}

\section{Q method}

To investigate subjective understandings, it is necessary to use a research method which can unveil cognitive processes which may take place below the level of full consciousness and might not be amenable to traditional research tools (Converse 2006). Q method was created to capture people's perspectives on a given issue (Stephenson 1953). It has been described as 'appropriate to questions about personal experience... and matters of taste, values and beliefs' (Baker 2006, p. 2343). Q is a participative and reflexive tool (Ockwell 2008) which minimises researcher bias through quantitative analysis (Eden et al. 2005). Q produces valid results from a small sample (Brown 2009) and its reliability has been demonstrated through test-retest studies (Brown 1980; Valenta and Wigger 1997).

Q works by identifying shared viewpoints over contested topics and statistically measuring participants' affinity to these views. It involves identifying an extensive "concourse" of items (usually statements but pictures are also possible) related to a particular issue from focus groups or academic literature or other sources. Items must be representative of all opinions on the issue which exist in the relevant community (Brown 1980). The concourse is then sampled to reduce the items to a manageable number (the 'Q set'). A group of participants then rank, or 'sort', the Q set and explain to the researcher their reasons for the ranking. The response of each participant is therefore a combination of the sort and their qualitative comments made during and after the sort (Watts and Stenner 2012). The researcher then uses factor analysis to group participants' responses into a small number of subjective understandings which can be summarised into narratives.

There is a growing literature which uses $\mathrm{Q}$ to give a richer understanding of socialenvironmental interactions (Ockwell 2008; Raadgever et al. 2008; Danielson 2009; Rastogi et al. 2013; Forrester et al. 2015; Pike et al. 2015). In the field of climate change, Q has been used to investigate climate thresholds (Niemeyer et al. 2005), perceptions (Wolf et al. 2009), images (O’Neill et al. 2013), public deliberations (Hobson and Niemeyer 2011) and adaptation (Živojinović and Wolfslehner 2015). Q 
has been used to investigate hurricane evacuation (Oakes 2014) and expert framings of environmental mobility (Morinière and Hamza 2012), but not to the author's knowledge, affected people's framings of environmental mobility.

Q is ideal for this study as it is used when the opinion of the participants is of central concern (Watts and Stenner 2012). In this context, the research question is focused on the understandings of the affected peoples in the three states. Furthermore, the oral storytelling culture (Janif et al. 2016) of Pacific SIDS lends itself to the qualitative and holistic nature of Q. Purely quantitative tools such as Likert scales may be unsuited to Islander participants as cultural and educational factors mean that statistics and probability may not be interpreted according to Western norms (Sharma 2016). Whilst it is true that the data collection for $\mathrm{Q}$ is a relatively complex operation for both researcher and participant, these challenges can be overcome with effective training and communication (Watts and Stenner 2012).

\section{Collection and sampling of statements}

To build the concourse, the author researched discourses relating to climate change and mobility in Kiribati, Tuvalu and Nauru in national and international newspapers, films, social media, journals and reports. Verbatim quotes were used where possible to preserve the essence of the opinions on the issues. Although it is true that the environment, society, economy and cultures vary both between and within countries, for simplicity and to enable comparison, discourses and statements common to each country were selected.

In the next stage, the author reduced the several hundred statements selected for the concourse to a manageable number for the Q set. Firstly, the author divided statements into nine distinct themes for sampling to ensure coverage and balance (Watts and Stenner 2012). Secondly, statements relating to climate change, mobility and adaptation were included as directly related to the research problem. Thirdly, as these issues take on importance in wider contexts, it was decided to include statements on the three pillars of sustainable development: environment, economy and society (WSSD 2002) which are also common reasons for moving in Pacific SIDS. Finally, the three themes discussed in the literature review as of particular importance to Pacific SIDS culture were included: religion, land and relocation/resettlement. It was decided to use 36 statements. This number produces valid data without becoming onerous for the participants (Barry and Proops 1999). Four statements were chosen for each theme to cover a variety of different angles. After the original statements were selected, the feedback was sought from local experts working with non-governmental organisations in the three countries. Through this evaluation process, several statements were edited or replaced. Finally, the statements were further fine-tuned through a pilot study in Fiji with migrants from the three countries. The statements were translated into the local languages. The English language final statements are shown in Table 1.

\section{Participant selection and the $\mathbf{Q}$ sort process}

The Q study fieldwork was undertaken at the same time as a large representative household survey carried out by the PCCM project research team designed to gather data on socio-economic indicators and migration history (Oakes et al. 2017). After participants had been surveyed, a quota sample was drawn according to age, gender, 
household income and mobility experiences to boost the chance of covering all viewpoints (Watts and Stenner 2012). In Kiribati, 24 people were interviewed, on four of the populated islands representing $6.4 \%$ of the total number of household surveys. In Tuvalu, 26 interviews were conducted in Funafuti, covering 15.3\% of surveys. In Nauru, 16 participants were interviewed in nine of the fourteen districts which equalled $9.7 \%$ of surveys.

Each Q sort was done in person under the instruction of a member of the research team who initially asked participants to sort the 36 statements printed on laminated cards into three piles: agree, disagree and indifferent. The researcher then asked the participants to further sort the three piles onto a normal- or bell-shaped grid. The columns of the grid were labelled from +4 (strongly agree), through zero to -4 (strongly disagree) as in Fig. 2. The researcher asked participants to think aloud whilst sorting to generate qualitative comments which the researcher recorded on paper. After the participants had completed the sort, the researcher asked participants to explain their reasons for the ranking of certain statements to provide context for analysis and then recorded both the sort and further qualitative comments on paper.

\section{Data analysis}

The author analysed the data for the three countries separately using factor analysis to produce results of relevance for each government. This was done by entering the sort (ranking of each statement by participant) into the programme PQ Method. Principal components analysis (PCA) was used to simplify complexity in the data whilst emphasising patterns (Lever et al. 2017). Varimax rotation was employed to maximise variance explained and increase the number of sorts associated with only one subjective understanding (Brown 1980). The author selected a subjective understanding for analysis if it fulfilled all three of the following criteria: it had an Eigenvalue greater than two, two or more people loaded significantly $(p \leq 0.05)$ on it, and it seemed distinct from other subjective understandings (Watts and Stenner 2012). Finally, narratives of the subjective understandings were written using a combination of the qualitative data collected in the interviews and the results of the factor analysis (Watts and Stenner 2012).

\section{Results}

The following section presents the results by country. As each subjective understanding is a composite of the responses of several participants loading on them, there can be contradictions within, and overlaps between subjective understandings. In this way, the results reflect complexities inherent in subjective realities. The responses of participants not loading on a subjective understanding are not considered for analysis as they do not share commonalities (Watts and Stenner 2012). Any quotes given are the precise words of participants.

\section{Kiribati}

The responses of 17 of the 24 participants in Kiribati were reduced to three subjective understandings (Table 2). Each of the three accepts that climate change is already impacting on livelihoods and subjective understanding 1 perceives this through faith. 
Table 1 The statements used for $Q$ method

\section{Statement}

Overarching themes

Sustainable Development
Climate Change

Migration

Adaptation

Environment

Economy

Society
I believe everyone on the island will be saved but with the help of others.

The angry sea will kill us all.

There are the high tides, but other than that not much is changing. Things have been pretty much the same for 30-40 years. So people are not very worried.

On our island there is nowhere to move back to - you'll either be in the lagoon or the ocean.

Here, a man might catch lots of fish one day and sell it, and the next day he can relax, sleep, visit friends and loaf around for the whole day. You cannot do that in New Zealand.

The young people go to the capital or Fiji, New Zealand, Australia or Samoa to study or to try to find a job. The old stay where they are.

If I could move temporarily to Australia or New Zealand then I would, but I would not want to move permanently.

If people move then they should send money back so that their families can remain at home.

First people will adapt to climate change, but if they cannot do more they may then migrate.

We need to do more to protect our coasts and water resources threatened by thoughtless pollution.

We look upon technology as our new salvation. But technology is not a creation of God. It is a creation of our own hands and in the end technology will turn around and become our greatest enemy.

If there is no food in the shop, we can eat pandanus, banana or coconut.

High tides and unseasonal storms are more and more frequent.

We are really not protected in any sustainable way at the moment.

Life is becoming impossible; either too much rain or long time of drought and lack of safe drinking water.

Higher water temperatures and ocean acidification are damaging the marine ecosystems that we depend on for food.

Family ties are really close here. That helps the inhabitants of the islands overcome many of the hardships and difficulties of living here.

Not everybody can migrate, so it's not a choice for the poor people. It's just a choice for the rich people.

The economy is picking up now but really slowly, but I reckon that we will get there.

There's no point getting a qualification if there is not going to be a job for you at the end.

The population pressure is now so great that a health catastrophe is coming. I would move to get access to better healthcare.

Houses are in bad condition because they cannot keep up with the costs of maintenance. They try to feed first their families.

Food security in the medium to long term is a serious concern as there is little agricultural activity. 
Table 1 (continued)

\begin{tabular}{l}
\hline Climate change will cause populations to move and perhaps \\
exacerbate this problem of urbanization and overcrowding. \\
I do not want to leave because I was born here. But if climate change \\
affects me I will have to leave. I feel very sad. It hurts to leave \\
where you come from. \\
Our people will be scattered, and the survival of our unique culture, \\
lifestyle and even our language, may be lost forever. \\
Our lands define who we are. Without a land, you are nobody. \\
We have the right to control our own destiny and resources. \\
Our reefs are healthy and can grow and rise with the sea level, so \\
there is absolutely no need to buy land in Fiji or anywhere else. \\
Relocation will always be viewed as an option of last resort. \\
Resettlement in some other location may be the only permanent and \\
definite solution...there is no other alternative. \\
Relieving population pressure through migration could help to \\
enhance the quality of life for those who remain. \\
Climate change is not God's curse, but a blessing in disguise. It \\
comes to test your faith and to produce in you the quality of \\
endurance. \\
The current changes in the weather and floods are signs of God \\
punishing wrongdoing. \\
If God says today is the day, then we stay here and go down with it. \\
Just as the chosen people of God got their land, I believe that we were \\
placed here and that the land is a gift from God. \\
Religion
\end{tabular}

Subjective understandings 1 and 3 are concerned about the impact of mobility on island culture; they are worried that it would not survive intact. Subjective understanding 1 appears to think an adaptation to a changing climate is possible, whilst 2 and 3 believe moving will be necessary.

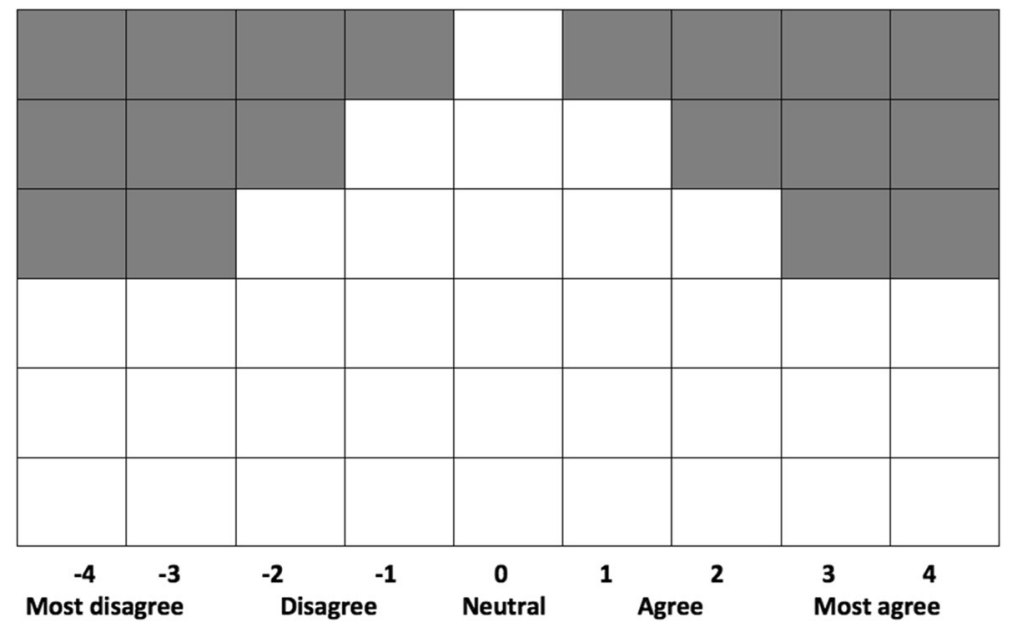

Fig. 2 The $Q$ grid 


\section{Subjective understanding 1: 'God will decide our fate'}

The first subjective understanding is defined by the importance given to religion, in particular, its relevance in understanding environmental threats. As one interviewee put it, 'God rules the world and whatever he wants we should appreciate'. However, there is also a feeling that 'God promised us there will be no flood, it is in the Bible'. Members of this group believe that the effect of climate change on the environment is significant and rising temperatures are already impacting marine ecosystems, although as yet there has been little effect on crops or catches. They believe that it is possible to adapt to the new environment or economic situation, with one participant confident that 'if there is no food at the market then still we can eat traditional food'. However, moving is viewed as problematic, as the land 'makes us known...is our identity and also our culture', suggesting the importance of fenua.

\section{Subjective understanding 2: 'Climate change is real; we will have to leave'}

This subjective understanding is pessimistic about the future under a changing climate as the statement members of this group rated the most highly was 'the angry sea will kill us all'. Climate change is seen as already occurring and caused by developed countries. Group members perceive that king tides are flooding crops, damaging trees, polluting the water supply and out-of-season storms are becoming more frequent. In contrast to the other subjective understandings, they are not confident that they can survive through traditional methods of gathering and fishing if it is not possible to buy food. These participants do not understand climate change and its impacts through religion, taking a more scientific framing. Whilst the group do not view migration or relocation favourably, they think it might be necessary. If mass mobility does take place, this group does not think that I-Kiribati culture will disappear; they think it is strong enough to survive.

\section{Subjective understanding 3: 'Climate change is a threat to our islands, population and culture'}

The participants who share this subjective understanding believe climate change is a very real threat and will likely result in large scale movements. As one participant explained, 'if a place is covered with fire, we should leave it'. Holders of this subjective understanding think that the environment has worsened over the last 30-40 years as

Table 2 Defining aspects of the subjective understandings for Kiribati

\begin{tabular}{|c|c|c|}
\hline 1. God will decide our fate & $\begin{array}{l}\text { 2. Climate change is real; we } \\
\text { will have to leave }\end{array}$ & $\begin{array}{l}\text { 3. Climate change is a threat to our } \\
\text { islands, population and culture }\end{array}$ \\
\hline $\begin{array}{l}\text { Importance given to the role of } \\
\text { God in Kiribati's future. } \\
\text { Religion provides the means to } \\
\text { understand climate risk, but } \\
\text { adaptation is possible. }\end{array}$ & $\begin{array}{l}\text { Angry and frustrated about the } \\
\text { future of Kiribati under a } \\
\text { changing climate. } \\
\text { Climate change will necessitate } \\
\text { mobility, but the I-Kiribati } \\
\text { culture will endure. }\end{array}$ & $\begin{array}{l}\text { Climate is a risk which may result in } \\
\text { mobility with serious implications } \\
\text { for I-Kiribati culture. } \\
\text { Mobility perceived as possibly having } \\
\text { a significant effect on } \\
\text { overpopulation. }\end{array}$ \\
\hline
\end{tabular}


king tides and storms are occurring more frequently and 'sea level rise turns our well water brackish'. This group does not see God as responsible for climate change or that God will decide Kiribati's fate. Despite their relatively low income, those who share this subjective understanding do not feel a lack of money constrains their ability to move. Whilst some think that mobility could help overcome the problem of overcrowding, others think it could worsen conditions. They are reluctant to leave their country but as one participant put it, 'if that time comes then I will find other country to live in'. They are pessimistic about what mobility means for the I-Kiribati and consider it a threat to their culture.

\section{Tuvalu}

Nineteen of the 26 participants in Tuvalu were statistically associated with one of four subjective understandings (Table 3). Subjective understanding 1 did not perceive climate change as a risk, whilst the others identified various climate-related hazards they are experiencing. Adaptation is a solution for subjective understandings 1 and 4 . Subjective understandings 2, 3 and 4 understand climate change partially through a religious perspective and believe faith can help Tuvaluans to deal with its consequences. Subjective understanding 2 thinks that migration must occur with dignity and shares with subjective understanding 4; the opinion that mobility is not always desirable, even if it is necessary. Subjective understanding 3 believes that complete relocation might become inevitable. Subjective understandings 1, 2 and 3 strongly feel that mobility would have a negative impact on culture.

\section{Subjective understanding 1: 'A resourceful people will adapt'}

The participants with this subjective understanding accept that climate change is real, but they have faith in Tuvaluans as a resourceful people who can overcome the challenges it presents. On the other hand, they also accept that mobility might be necessary. Members of this group recognise the threats that king tides might pose, but believe environmental impacts are not necessarily worse than in the past and relocation is viewed as a last resort. As one participant put it 'we should use our brain. If we see the island is uninhabitable then we should do something about it rather than going

Table 3 Defining aspects of the subjective understandings for Tuvalu

\begin{tabular}{|c|c|c|c|}
\hline $\begin{array}{l}\text { 1. 'A resourceful } \\
\text { people will adapt' }\end{array}$ & $\begin{array}{l}\text { 2. 'We need dignified } \\
\text { migration from the } \\
\text { inevitable' }\end{array}$ & $\begin{array}{l}\text { 3. 'Climate change } \\
\text { is already here; relocation } \\
\text { might be the only answer' }\end{array}$ & $\begin{array}{l}\text { 4. 'Our faith and } \\
\text { community will overcome' }\end{array}$ \\
\hline $\begin{array}{l}\text { Relatively optimistic } \\
\text { about the future and } \\
\text { climate change. } \\
\text { The community can } \\
\text { pull together to be } \\
\text { overcome threats. }\end{array}$ & $\begin{array}{l}\text { Moving may be } \\
\text { inevitable but it needs } \\
\text { to be on Tuvaluans' } \\
\text { terms. } \\
\text { Sense of anxiety over } \\
\text { what mobility will } \\
\text { mean for Tuvaluans } \\
\text { and their culture. }\end{array}$ & $\begin{array}{l}\text { Already experiencing the } \\
\text { impacts of climate } \\
\text { change including on } \\
\text { housing. } \\
\text { Relocation may be a } \\
\text { solution. }\end{array}$ & $\begin{array}{l}\text { Religion and national and } \\
\text { regional networks will } \\
\text { enable Tuvalu to } \\
\text { respond to climate risks. } \\
\text { Rejection that God offers } \\
\text { protection } \\
\text { from flooding. }\end{array}$ \\
\hline
\end{tabular}


down with it'. Perhaps, this optimism is related to the high level of the mean income of the people who comprise this group. They are worried about the impact that mobility will have on Tuvaluan society but believe climate change is 'not God-given punishments', rather it is happening 'because of mankind's neglect and ignorance'.

\section{Subjective understanding 2: 'We need dignified migration from the inevitable'}

Under this subjective understanding, moving will probably be necessary but should be on the Tuvaluans' terms. Flooding is a significant risk and people have little power over climate change; it might even be God's will. Some people may stay to the bitter end, but there is also a belief that Tuvalu was a gift from God who promised to Noah that there will not be another flood. As one interviewee explained, Tuvalu 'is where I belong, my true identity and also it is where I was brought up' and leaving will 'result in the loss of culture'. In addition, destinations might have more 'crises compared to my country which is free from these problems'. At the same time, there is a belief that better opportunities for work and education lie abroad.

\section{Subjective understanding 3: 'Climate change is already here; relocation might be the only answer'}

The participants who share this subjective understanding have a strong sense that climate change is affecting the environment and it might be prudent to move before it is too late. They are worried about the impacts of flooding on crops, trees and water supply and highlighted changes in rainfall whilst 'drought affects people most'. Housing on Funafuti was also identified as a problem which will worsen under climate change. Participants worry that by moving, Tuvaluan culture will be impacted but relocation might be the only viable option: "we should try to think of the ways to evacuate now...before it is too late'. Scientific understandings of climate change exist in tandem with religious faith with one interviewee stating 'God chose me to be on this island and He promised in Genesis that there will be no flood until He returns'.

\section{Subjective understanding 4: 'Our faith and community will overcome'}

Participants within this subjective understanding believe their religion and faith in the wider Pacific community will enable Tuvalu to overcome climate change impacts. As one participant claimed, due to the 'geography and size of the land here in Tuvalu, it's possible for...everyone to die'. The saltwater intrusion was identified as a threat, with one participant explaining that 'the water taste would become more saline, making it unsuitable for drinking'. There is a strong sense of identity within the region, with one participant taking solace that 'our friends from Australia and New Zealand helped us...during Cyclone Pam'. Migration to these countries is not necessarily viewed as desirable, although a foreign education is seen as an opportunity. For this group, religious faith can provide strength to the community as 'the Bible said we have to pray and do something, we can't do everything but we do something'. 


\section{Nauru}

Of the 16 participants interviewed in Nauru, 12 exhibited one of three shared subjective understandings and all three demonstrate a belief that the environment is being affected by climate change (Table 4). Subjective understanding 2 shows that some Nauruans understand climate change through their religion. Subjective understandings 2 and 3 think that migration might be desirable and subjective understandings 1 and 3 think that adaptation is possible for a proud nation through family ties. The Nauru study provided some evidence of trapped populations. Even though Nauru has the highest mean income of the three countries, subjective understandings 2 and 3 alluded to people not having the material means to migrate.

\section{Subjective understanding 1: 'If it comes to the worst, I would leave'}

Through this subjective understanding, participants perceive climate change and mobility as having a serious impact on Nauruan culture, but feel that the community is resilient enough to remain or move in an adaptive manner. Participants are aware of the threat of climate change as it is 'gradually washing away our land and self-sufficiency is becoming problematic as I am unable to go fishing'. Another participant explained 'if it comes to the worst, I would leave'. Despite this, they do not think that they are doomed. They see strength in the community as 'Nauruans value family ties very much and no matter what hardship we face, we can always rely on family to help' with staying or moving. This ability to access assistance may reflect the high level of education and income of the participants in this group relative to other Nauruans.

\section{Subjective understanding 2: 'Reefs and beaches won't protect us'}

The participants associated with this subjective understanding are somewhat resigned; they believe they have little power to prevent climate change, adapt to it, or move away from it. For this reason, it could be argued that these participants feel trapped. They do not think that sea level rise can be overcome through physical barriers as 'reefs and beaches won't protect us from king tides and unseasonal storms'. They highlight the limited space on Nauru which offers few options to move domestically and see

Table 4 Defining aspects of the subjective understandings for Nauru

\begin{tabular}{|c|c|c|}
\hline $\begin{array}{l}\text { 1. 'If it comes to the worst, I } \\
\text { would leave' }\end{array}$ & $\begin{array}{l}\text { 2. 'Reefs and beaches won't protect } \\
\text { us' }\end{array}$ & 3. 'Migration is for everyone' \\
\hline $\begin{array}{l}\text { Perceive serious problems but } \\
\text { feel that the community can } \\
\text { overcome many of the } \\
\text { difficulties faced. } \\
\text { Nonetheless, concerned about } \\
\text { the impact of climate change } \\
\text { and migration on the } \\
\text { Nauruan culture. }\end{array}$ & $\begin{array}{l}\text { Resigned to climate change and } \\
\text { somewhat fatalistic with regard to } \\
\text { environmental threats. } \\
\text { Little power to prevent climate } \\
\text { change, adapt to it or move away } \\
\text { from it. Feel trapped. }\end{array}$ & $\begin{array}{l}\text { Egalitarian views on climate } \\
\text { change, migration and } \\
\text { human rights. } \\
\text { Adaptation is considered } \\
\text { possible through domestic } \\
\text { networks and resources. }\end{array}$ \\
\hline
\end{tabular}


international mobility limited by material factors for poorer members of society. They also see a clear connection between God and climate change. On the one hand, they believe God will protect Nauru. On the other hand, there is a belief that if the island is flooded, some Nauruans may stay and accept their fate.

\section{Subjective understanding 3: 'Migration is for everyone'}

Subjective understanding 3 can be termed egalitarian, to reflect the views which the participants hold on climate change, mobility and human rights. These people recognise the importance of the land for the people of Nauru, with one participant pointing out 'because I was born in Nauru, I don't want to leave, but climate change makes me move'. Migration is not seen as only an option for the rich, 'but it's for everyone who want to migrate to another country'. This could be influenced by the relatively low incomes of these participants. They believe it is possible to adapt to a changing climate and adverse economy through their family ties and through eating locally available produce. One of the participants believes that 'people should stay on the island; floods and sea level rise only affect the coast'.

\section{Discussion}

There are key differences in the relative importance given to various issues within the subjective understandings of climate change and mobility across the three countries. Kiribati is the country in which climate change is most strongly understood as an existential threat to culture and mobility is viewed most ambivalently. Whilst one of the subjective understandings of Kiribati is the most fatalistic, Tuvalu is the country in which religious framings of climate change and in situ adaptation are most prominent. Nauru is the country in which mobility is most firmly viewed as an issue of equality and as a form of adaptation enabled through family and networks.

There are also a variety of understandings of the existence, severity and effects of climate change across the three countries. For some, there has been little change and challenges can be overcome through local knowledge, familial ties and the help of regional powers. For others, the change has been dramatic, and the situation is quite hopeless, especially in Kiribati. Perceptions of mobility are also differentiated, although mobility as a positive adaptation to a changing environment is not a major theme which emerges. Mobility is more likely to be considered a way of life for work and education, or a necessary evil caused by environmental degradation. Further, the holders of one subjective understanding in Tuvalu believe that although there are environmental or other problems, the alternative may not be superior. This supports Adam's (Adams 2016) contention that mobility decisions are made considering potential losses and gains. In each country, there is also a belief that some populations will be unable to leave due to material reasons, with this feeling strong in Nauru where domestic mobility is impossible.

Religion is central in the three countries, existing in tandem with scientific understandings. Religion influences some residents to move or otherwise adapt in place to the impacts of climate change. For some, faith promotes what a risk management professional might term risk-seeking behaviour such as refusing to move due to the 
belief that God will protect the island from the impacts of climate change (Farbotko 2005). It is possible this could be a response to limited agency, if people are unable to move, they may take on a worldview that a higher power will provide protection (Kelman et al. 2015). In this way, culture may have evolved as an adaptation to the changing environment (Steward 1972). For others, religious faith provides the strength necessary to take the difficult decision to move, as well as the cultural capital to make a success of it. As a result, it is not possible to state whether religion promotes or hinders mobility or other climate-related adaptive behaviour, rather outcomes are influenced by individual interpretations of religious beliefs and the actions that follow.

The study found evidence of strong place attachment in each of the three countries. For some in Tuvalu, the threat of having to find new homes in other regions detached from the communities they grew up in and away from the lands of their ancestors can contribute to a reluctance to leave - echoing the views of their Prime Minister. In Nauru, climate change may be viewed as lessening the already limited space. The Government of Kiribati has recently acquired large amounts of land in Fiji, officially for food security, although many I-Kiribati believe it is to provide future mobility opportunities (Hermann and Kempf 2017). This study suggests many I-Kiribati would be reluctant to leave their islands and country, whilst the household survey conducted alongside Q method revealed that Fiji is not the most popular potential international destination (Oakes et al. 2016). Other research has found that New Zealand is deemed a more attractive proposition due to the existing networks and potential employment opportunities (Stratford et al. 2013). This raises questions about whether households will be willing and able to adapt to different islands, livelihoods and cultures.

The study supports a broader understanding of trapped populations (Warner and Laczko 2008). The dominant framing of trapped populations is a simplification, potentially constraining on the agency of people concerned. In fact, people may be immobile for reasons that are not only related to socio-economic status or the political realities of moving (Adams 2016). People bear certain climate change-related impacts to livelihoods which they deem tolerable to avoid those they consider unacceptable, namely loss of home and culture. Yet, these endogenous barriers have limits and people seemingly decide at varied levels of consciousness whether and when to move. The threshold after which the desire to leave outstrips the anchoring power of staying is dependent on objective realities such as financial and legal ability to move, but also subjective understandings of home, hopes and fears of life in a new place and if people believe they have the ability to move. As such, they may remain in objectively risky areas as they subjectively perceive their current lives and risks as preferable to the known or unknown alternatives.

\section{Conclusion and policy implications}

The subjective approach adopted for this study demonstrates that Pacific Islanders hold a range of perspectives on climate change and mobility. Most subjective understandings perceive climate change as a risk requiring responses in the present and future, including adaptation and mobility. Whilst some people think that they will be able to adapt or move, others feel powerless as lacking the material capacity or apparently content to let fate take its course. The study also reflects the indelible links between 
motivations and outcomes. Islanders navigate the risks and reward of mobility through their subjective understandings and the relative importance they ascribe to the economy, environment and society in destinations relative to their present locations and lives. A cultural ecology standpoint shows these understandings are informed by material and ideational cultures and especially the centrality of land and religion.

Such findings can inform domestic policy makers and practitioners to better respond to Pacific Islanders' desires and actions. Investment in education, healthcare and economic opportunities can bolster agential reasons to stay. In addition, further incorporating disaster risk reduction, climate change adaptation and resilience into development planning can contribute to more sustainable livelihoods. Such policies can increase the chances of dignified migration for those who want to move whilst they still have options about if, when and how to move, what to do on arrival and if, and when to return. The findings also have implications for international policy. There is a strong belief within the Pacific SIDS that migration with dignity should be for everybody. Due to the lack of freshwater, land and economic opportunities in Pacific SIDS, benefits to migrants, households, sending and host communities will be higher if they move internationally. For this to occur, there needs to be an increase in the depth and breadth of partnerships between sending and receiving countries in addition to better developed links with diaspora to smooth the cultural challenges mobility brings. Without these changes, Pacific Islanders will continue to face restricted choices, limiting their agency, and resulting in internal, potentially unsustainable movements.

Climate-related mobility in Pacific SIDS is a complex conceptualisation and process; the result of objective risks, material ability to cope with these risks, and as demonstrated by this study, the subjective understandings of these risks and mobility. To reduce the issue to one or two framings whilst failing to recognise, understand and validate this complexity may result in false assumptions about Pacific Islander desires and responses, and so ineffective policy. Above all, if climate risks, mobility and decisions are perceived differently and through the prism of culture, then they should also be addressed through a differentiated and participatory approach, mindful of culture and especially of land and religion. Therefore, by foregrounding Islander perspectives, innovative research methods such as Q can provide improved knowledge for nuanced policy at the nexus of climate risk and mobility.

\section{Compliance with ethical standards}

All experiments comply with the current laws of the country in which they were performed.

\section{References}

Adams, H. (2016). Why populations persist: mobility, place attachment and climate change. Population and Environment, 37(4), 429-448.

Adger, W. N., Dessai, S., Goulden, M., Hulme, M., Lorenzoni, I., Nelson, D. R., Naess, L. O., Wolf, J., \& Wreford, A. (2009). Are there social limits to adaptation to climate change? Climatic Change, 93(3-4), 335-354.

Adger, W. N., Barnett, J., Chapin, F. S., III, \& Ellemor, H. (2011). This must be the place: underrepresentation of identity and meaning in climate change decision-making. Global Environmental Politics, 11(2), 1-25.

Adger, W. N., Barnett, J., Brown, K., Marshall, N., \& O’Brien, K. (2013). Cultural dimensions of climate change impacts and adaptation. Nature Climate Change, 3(2), 112-117. 
Agyeman, J., Devine-Wright, P. and Prange, J., (2009). Close to the edge, down by the river? Joining up managed retreat and place attachment in a climate changed world. Environment and Planning A, 41(3), 509-513.

Allgood, L., \& McNamara, K. E. (2017). Climate-induced migration: exploring local perspectives in Kiribati. Singapore Journal of Tropical Geography, 38(3), 370-385.

Ash, J., \& Campbell, J. (2016). Climate change and migration: the case of the Pacific Islands and Australia. Journal of Pacific Studies, 36(1), 53-72.

Baker, R. M. (2006). Economic rationality and health and lifestyle choices for people with diabetes. Social Science \& Medicine, 63, 2341-2353.

Barnett, J. and Campbell, J., (2010). Climate change and small island states: power, knowledge, and the South Pacific. Earthscan.

Barry, J., \& Proops, J. (1999). Seeking sustainability discourses with Q methodology. Ecological Economics, 28(3), 337-345.

Berry, J.W., (2018). "Ecocultural perspective on human behavior". Üskül, A.K. and Oishi, S. eds. Socioeconomic environment and human psychology: social, ecological, and cultural perspectives. Oxford University press.

Bertram, G., (1999). The MIRAB model twelve years on. The Contemporary Pacific, pp105-138.

Bettini, G. (2014). Climate migration as an adaption strategy: desecuritizing climate-induced migration or making the unruly governable? Critical Studies on Security, 2, 180-195.

Black, R. and Collyer, M., (2014). Populations 'trapped' at times of crisis. Forced Migration Review, (45), p.52.

Borjas, G.J., (1989). Economic theory and international migration. International migration review, pp.457-485.

Brookings and UNHCR (2015) Guidance on Planned Relocation http://www.unhcr. org/uk/protection/environment/562f798d9/planned-relocation-guidance-october-2015.html

Brown, S., (1980). Political subjectivity: applications of Q methodology in political science, Yale University Press.

Brown, S. R. (2009). Q technique, method, and methodology: comments on Stentor Danielson's article. Field Methods, 21(3), 238-241.

Burkett, M. (2011). The nation ex-situ: on climate change, deterritorialized nationhood and the post-climate era. Climate law, 2(3), 345-374.

Campbell, J., Oakes, R., and Milan, A. (2016). Nauru: climate change and migration - relationships between household vulnerability, human mobility and climate change no.19 Bonn: United Nations University Institute for Environment and Human Security (UNU-EHS). http://collections.unu.edu/view/UNU:5902

Connell, J. (2011). Elephants in the Pacific? Pacific urbanisation and its discontents. Asia Pacific Viewpoint, 52, 121-135. https://doi.org/10.1111/j.1467-8373.2011.01445.x.

Connell, J. (2012). Population resettlement in the Pacific: lessons from a hazardous history? Australian Geographer, 43(2), 127-142.

Connell, J. (2013). Soothing breezes? Island perspectives on climate change and migration. Australian Geographer, 44(4), 465-480.

Converse, P. E. (2006). The nature of belief systems in mass publics (1964). Critical Review, 18(1-3), 1-74.

CSIRO (2011). Climate change in the Pacific: scientific assessment and new research. Volume 1: Regional Overview. Volume 2: Country Reports.

Danielson, S. (2009). Q method and surveys: three ways to combine Q and R. Field Methods, 21, $219-237$.

Donner, S. D. (2015). The legacy of migration in response to climate stress: learning from the Gilbertese resettlement in the Solomon Islands. Natural Resources Forum, 39(3-4), 191-201.

Douglas, M. (1992). Risk and blame: essays in cultural theory. London: Routledge.

Drabek, T.E., (1986). Human system responses to disaster: an inventory of sociological findings, SpringerVerlag.

Eden, S., Donaldson, A., \& Walker, G. (2005). Structuring subjectivities? Using Q methodology in human geography. Area, 37(4), 413-422.

Farbotko, C. (2005). Tuvalu and climate change: constructions of environmental displacement in the Sydney Morning Herald. Geografiska Annaler: Series B, Human Geography, 87(4), 279-293.

Farbotko, C., \& Lazrus, H. (2012). The first climate refugees? Contesting global narratives of climate change in Tuvalu. Global Environmental Change, 22(2), 382-390.

Farbotko, C., Stratford, E., \& Lazrus, H. (2015). Climate migrants and new identities? The geopolitics of embracing or rejecting mobility. Social \& Cultural Geography, 1-20.

Fielding, T. (1992). Migration and culture. Migration processes and patterns, 1, 201-212.

Foresight, U.K., 2011. Foresight: migration and global environmental change: final project report. The Government Office for Science, London. 
Forrester, J., Cook, B., Bracken, L., Cinderby, S., \& Donaldson, A. (2015). Combining participatory mapping with Q-methodology to map stakeholder perceptions of complex environmental problems. Applied Geography, 56, 199-208.

Gemenne, F. and Blocher, J., (2017). How can migration serve adaptation to climate change? Challenges to fleshing out a policy ideal. The Geographical Journal.

Goldsmith, M. (2015). The big smallness of Tuvalu. Global Environment, 8(1), 134-151.

Goodenough, W. H. (1957). "Cultural anthropology and linguistics". Report of the Seventh Annual Round Table Meeting on Linguistics and Language Study, ed. P. Garvin. Washington, D.C.: Georgetown.

Government of Tuvalu (2015). 2012 Population \& Housing Census Preliminary Analytical Report. Tuvalu Central Statistics Division.

Grothmann, T., \& Patt, A. (2005). Adaptive capacity and human cognition: the process of individual adaptation to climate change. Global Environmental Change, 15(3), 199-213.

Hermann, E., \& Kempf, W. (2017). Climate change and the imagining of migration: emerging discourses on Kiribati's land purchase in Fiji. The Contemporary Pacific, 29(2), 231-263.

Hirsch, E. (2015). "It won't be any good to have democracy if we don't have a country": climate change and the politics of synecdoche in the Maldives. Global Environmental Change, 35, 190-198.

Hobson, K., \& Niemeyer, S. (2011). Public responses to climate change: the role of deliberation in building capacity for adaptive action. Global Environmental Change, 21(3), 957-971.

Hugo, G. (2011). Future demographic change and its interactions with migration and climate change. Global Environmental Change, 21, S21-S33.

IDMC (2017). Global Report on Internal Displacement. Internal Displacement Monitoring Centre. http://www.internal-displacement.org/global-report/grid2017/\#download

International Organization for Migration, Hugo Observatory (University of Liège), Norwegian Refugee Council (including IDMC) and UNU-EHS (2016). Synthesis to the Warsaw International Mechanism Executive Committee of relevant information, good practices and lessons learned in relation to Pillar 1: enhancing knowledge and understanding. http://unfccc.int/files/adaptation/groups_committees/loss_and_ damage_executive_committee/application/pdf/excom_iom_technical_meeting_pillar_1.pdf

IOM. (2017). Making mobility work for adaptation to environmental changes: results from the MECLEP global research. Geneva: International Organization for Migration.

IPCC (2014) Climate change 2014: impacts, adaptation, and vulnerability - part A: global and sectoral aspects. In eds. C.B Field and others, Contribution of Working Group II to the Fifth Assessment Report of the Intergovernmental Panel on Climate Change. Cambridge and New York: Cambridge University Press.

Janif, S. Z., Nunn, P. D., Geraghty, P., Aalbersberg, W., Thomas, F. R., \& Camailakeba, M. (2016). Value of traditional oral narratives in building climate-change resilience: insights from rural communities in Fiji. Ecology and Society, 21(2).

Kahan, D. M., Braman, D., Gastil, J., Slovic, P. and Mertz, C. K., (2007). Culture and identity-protective cognition: Explaining the white-male effect in risk perception. Journal of Empirical Legal Studies, 4(3), 465-505.

Kahneman, D., (2012). Thinking, fast and slow, Penguin.

Kasperson, R. E., Renn, O., Slovic, P., Brown, H. S., Emel, J., Goble, R., Kasperson, J. X., \& Ratick, S. (1988). The social amplification of risk: a conceptual framework. Risk Analysis, 8(2), 177-187.

Keesing, R. M. (1974). Theories of culture. Annual Review of Anthropology, 3(1), 73-97.

Kelman, I., Stojanov, R., Khan, S., Gila, O. A., Duz, B., \& Vikhrov, D. (2015). Viewpoint paper. Islander mobilities: any change from climate change? International Journal of Global Warming, 8, 584-602.

Kirch, P.V., (2017). On the road of the winds: an archaeological history of the Pacific Islands before European contact. University of California Press.

Kuruppu, N. (2009). Adapting water resources to climate change in Kiribati: the importance of cultural values and meanings. Environmental Science \& Policy, 12(7), 799-809.

Lever, J., Krzywinski, M., \& Altman, N. (2017). Points of significance: principal component analysis. Nature Methods, 14, 641-642.

Lindell, M. K., Lu, J.-C., \& Prater, C. S. (2005). Household decision making and evacuation in response to hurricane Lili. Natural Hazards Review, 6(4), 171-179.

Locke, J. T. (2009). Climate change-induced migration in the Pacific Region: sudden crisis and long-term developments 1. The Geographical Journal, 175(3), 171-180.

Manzello, D.P., Eakin, C.M. and Glynn, P.W., (2017). Effects of global warming and ocean acidification on carbonate budgets of eastern Pacific coral reefs. In coral reefs of the eastern tropical Pacific (pp. 517-533). Springer Netherlands.

Massey, D.S., Arango, J., Hugo, G., Kouaouci, A., Pellegrino, A. and Taylor, J.E., (1993). Theories of international migration: a review and appraisal. Population and development review, pp.431-466. 
McCubbin, S., Smit, B., \& Pearce, T. (2015). Where does climate fit? Vulnerability to climate change in the context of multiple stressors in Funafuti, Tuvalu. Global Environmental Change, 30, 43-55.

McIvor, D., \& Paton, D. (2007). Preparing for natural hazards: normative and attitudinal influences. Disaster Prevention and Management, 16(1), 79-88.

McNamara, K. E. (2015). Cross-border migration with dignity in Kiribati. Forced Migration Review, 49, 6262.

Milan, A., Oakes, R., and Campbell, J. (2016). Tuvalu: climate change and migration -relationships between household vulnerability, human mobility and climate change. Report No. 18. Bonn: United Nations University Institute for Environment and Human Security (UNU-EHS). http://collections.unu. edu/view/UNU:5856

Morinière, L. C. E., \& Hamza, M. (2012). Environment and mobility: a view from four discourses. Ambio, 41(8), 795-807.

Mortreux, C., \& Barnett, J. (2009). Climate change, migration and adaptation in Funafuti, Tuvalu. Global Environmental Change, 19(1), 105-112.

Myers, N. (1993). Environmental refugees in a globally warmed world. BioScience, 43(11), 752-161.

Niemeyer, S., Petts, J., \& Hobson, K. (2005). Rapid climate change and society: assessing responses and thresholds. Risk Analysis, 25(6), 1443-1456.

Noy, I., (2017). To leave or not to leave? Climate change, exit, and voice on a Pacific Island. CESifo Economic Studies, p.ifx004.

Nunn, P. D., Mulgrew, K., Scott-Parker, B., Hine, D. W., Marks, A. D., Mahar, D., \& Maebuta, J. (2016). Spirituality and attitudes towards nature in the Pacific Islands: insights for enabling climate-change adaptation. Climatic Change, 136(3-4), 477-493.

O'Neill, S. J., Boykoff, M., Niemeyer, S., \& Day, S. A. (2013). On the use of imagery for climate change engagement. Global Environmental Change, 23(2), 413-421.

Oakes, R.D., (2014). Using Q method and agent based modelling to understand hurricane evacuation decisions (Doctoral dissertation, University of Sussex).

Oakes, R., Milan, A., and Campbell, J. (2016). Kiribati: climate change and migration - relationships between household vulnerability, human mobility and climate change. Report No. 20. Bonn: United Nations University Institute for Environment and Human Security (UNU-EHS). http://collections.unu. edu/view/UNU:5903

Oakes, R., Milan, A., and Schindler, M. (2017). Research methods for the Pacific Climate Change and Migration (PCCM) project. Bonn: United Nations University Institute for Environment and Human Security (UNU-EHS). http://collections.unu.edu/eserv/UNU:5856/Research_Methods_for_PCCM_ Project.pdf

O'Brien, K. L., \& Wolf, J. (2010). A values-based approach to vulnerability and adaptation to climate change. Wiley Interdisciplinary Reviews: Climate Change, 1(2), 232-242.

Ockwell, D. G. (2008). 'Opening up' policy to reflexive appraisal: a role for Q methodology? A case study of fire management in Cape York, Australia. Policy Sciences, 41, 263-292.

Oliver-Smith, A. (1996). Anthropological research on hazards and disasters. Annual Review of Anthropology, 303-328.

Oliver-Smith, A., (2016). The concepts of adaptation, vulnerability, and resilience in the anthropology of climate change: considering the case of displacement and migration. Anthropology and Climate Change: From Actions to Transformations, p.58.

Peacock, W.G., Morrow, B.H. and Gladwin, H., (1997). Hurricane Andrew: ethnicity, gender, and the sociology of disasters, Routledge.

Pike, K., Wright, P., Wink, B., \& Fletcher, S. (2015). The assessment of cultural ecosystem services in the marine environment using Q methodology. Journal of Coastal Conservation, 19(5), 667-675.

Piore, M. J. (1979). Birds of passage: migrant labor and industrial societies. Cambridge: Cambridge University Press.

Raadgever, G., Mostert, E., \& Van de Giesen, N. (2008). Identification of stakeholder perspectives on future flood management in the Rhine basin using Q methodology. Hydrology and Earth System Sciences, 12(4), 1097-1109.

Ransan-Cooper, H., Farbotko, C., McNamara, K. E., Thornton, F., \& Chevalier, E. (2015). Being(s) framed: the means and ends of framing environmental migrants. Global Environmental Change, 35, 106-115.

Rastogi, A., Hickey, G. M., Badola, R., \& Hussain, S. A. (2013). Diverging viewpoints on tiger conservation: a Q-method study and survey of conservation professionals in India. Biological Conservation, 161, 182192.

Republic of Kiribati, (2016). 2015 Population and Housing Census. Volume 1: Management Report and Basic Tables. National Statistics Office, Ministry of Finance, Bairiki, Tarawa. 
Republic of Nauru (2011). Population and Housing Census. http://www.spc.int/nmdi/nmdi_documents/2011_ NAURU_CENSUS_REPORT.pdf. Accessed 3 April 2019.

Rigaud, K.K., de Sherbinin, A., Jones, B., Bergmann, J., Clement, V., Ober, K., Schewe, J., Adamo, S., McCusker, B., Heuser, S. and Midgley, A., (2018). Groundswell: preparing for internal climate migration. World Bank.

Scott, S. (2006). The social morphology of skilled migration: the case of the British middle class in Paris. Journal of Ethnic and Migration Studies, 32(7), 1105-1129.

Sharma, S. (2016). How do Pasifika students reason about probability? Some findings from Fiji. Waikato Journal of Education, 12(1).

Shen, S., \& Gemenne, F. (2011). Contrasted views on environmental change and migration: the case of Tuvaluan migration to New Zealand. International Migration, 49(s1), e224-e242.

Slovic, P. (2000). The perception of risk, London. Sterling, VA: Earthscan Publications.

Smith, R. (2013). Should they stay or should they go? A discourse analysis of factors influencing relocation decisions among the outer islands of Tuvalu and Kiribati. Journal of New Zealand and Pacific Studies, I(1), 23-39.

Sopoanga, E.S., (2016). Key note opening address presented by Honourable Enele Sosene Sopoanga at the opening of the regional meeting on climate change and migration workshop 7 December 2016. Suva, Fiji.

Stark, O., \& Bloom, D. E. (1985). The new economics of labor migration. The American Economic Review, 75(2), 173-178.

Stephenson, W. (1953). The study of behavior: Q-technique and its methodology. Chicago: University of Chicago Press.

Steward, J.H., (1972). Theory of culture change: the methodology of multilinear evolution. University of Illinois Press.

Storey, D., \& Hunter, S. (2010). Kiribati: an environmental 'perfect storm'. Australian Geographer, 41(2), $167-181$.

Stratford, E., Farbotko, C., \& Lazrus, H. (2013). Tuvalu, sovereignty and climate change: considering Fenua, the archipelago and emigration. Island Studies Journal, 8(1), 67-83.

Svašek, M. (2010). On the move: emotions and human mobility. Journal of Ethnic and Migration Studies, $36(6), 865-880$.

Tabucanon, G. (2012). The banaban resettlement: implications for Pacific environmental migration. Pacific Studies, 35(3), 343-370.

Tabucanon, G. M., \& Opeskin, B. (2011). The resettlement of Nauruans in Australia: an early case of failed environmental migration. Journal of Pacific History, 46(3), 337-356.

Tacoli, C. (2009). Crisis or adaptation? Migration and climate change in a context of high mobility. Environment and Urbanization, 21(2), 513-525.

UNCTAD. (2018). The Least Developed Countries Report 2018: entrepreneurship for structural transformation: Beyond business as usual. New York: United Nations publication.

UNESCAP. (2014). Climate change and migration issues in the Pacific. Fiji: United Nations.

UNFCCC (1999). Republic of Nauru response, 1st National Communication - 1999, climate change-response under the United Nations Framework Convention on Climate Change. Nauru's National Committee on climate change, the Energy Unit of the South Pacific Applied Geoscience Commission (SOPAC). URL: http://unfccc.int/resource/docs/natc/naunc1.pdf.

UNFCCC (2015). Adoption of the Paris Agreement. 21st Conference of the Parties to the United Nations Framework Convention on Climate Change (COP21). December 13, 2015. http://unfecc. int/resource/docs/2015/cop21/eng/109.pdf

UNFCCC (2017). Report of the Executive Committee of the Warsaw International Mechanism for loss and damage associated with climate change impacts. https:/unfccc.int/sites/default/files/resource/docs/2017 /sb/eng/01a01e.pdf

Unicef UK (2017). No place to call home: protecting children's rights when the changing climate forces them to flee. https://downloads.unicef.org.uk/wp-content/uploads/2017/04/No-Place-To-Call-Home.pdf?_ $\mathrm{ga}=2.73316244 .623674493 .1494945170-1964912592.1483624860$

Valenta, A. L., \& Wigger, U. (1997). Q-methodology: definition and application in health care informatics. Journal of the American Medical Informatics Association, 4(6), 501-510.

Verwiebe, R. (2014). Why do Europeans migrate to Berlin? Social-structural differences for Italian, British, French and Polish nationals in the period between 1980 and 2002. International Migration, 52(4), 209230.

Voigt-Graf, C. and Kagan, S, (2017) Migration and labour mobility from Kiribati. Development Policy Centre Discussion Paper No. 56. Available at SSRN: https://ssrn.com/abstract=2937416 or https://doi. org $/ 10.2139 / \mathrm{ssrn} .2937416$ 
Warner, K., \& Afifi, T. (2014). Where the rain falls: evidence from 8 countries on how vulnerable households use migration to manage the risk of rainfall variability and food insecurity. Climate and Development, $6(1), 1-17$.

Warner, K., \& Laczko, F. (2008). Migration, environment and development: new directions for research. Center for Migration Studies special issues, 21(1), 235-251.

Watts, S. and Stenner, P., (2012). Doing Q methodological research: theory, method \& interpretation, Sage Publications Ltd.

Weber, E. (2015) Envisioning South-South relations in the fields of environmental change and migration in the Pacific Islands - past, present and futures. Bandung: Journal of the Global South, 2(1) Available: www. bandungjournal.com/content/pdf/s40728-014-0009-z.pdf

Wolf, J., Brown, K., \& Conway, D. (2009). Ecological citizenship and climate change: perceptions and practice. Environmental Politics, 18(4), 503-521.

WSSD (2002) The Johannesburg Declaration on Sustainable Development, 4 September 2002, http://www. housing.gov.za/content/legislation_policies/johannesburg.htm.

Zickgraf, C., 2018. Immobility. In Routledge Handbook of environmental displacement and migration (pp. 7184). Routledge.

Živojinović, I., \& Wolfslehner, B. (2015). Perceptions of urban forestry stakeholders about climate change adaptation-a Q-method application in Serbia. Urban Forestry \& Urban Greening, 14(4), 1079-1087.

Publisher's note Springer Nature remains neutral with regard to jurisdictional claims in published maps and institutional affiliations. 